\title{
Control of cardiovascular responses to stress by CRF in the bed nucleus of stria terminalis is mediated by local NMDA/nNOS/sGC/PKG signaling
}

\author{
Leandro A. Oliveira ${ }^{\mathrm{a}, \mathrm{b}}$, Lucas Gomes-de-Souza ${ }^{\mathrm{a}, \mathrm{b}}$, Ricardo Benini ${ }^{\mathrm{a}, \mathrm{b}}$, Carlos C. Crestani ${ }^{\mathrm{a}, \mathrm{b}, *}$

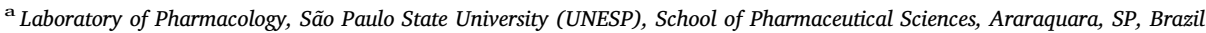 \\ b Joint UFSCar-UNESP Graduate Program in Physiological Sciences, São Carlos, SP, Brazil
}

\section{A R T I C L E I N F O}

\section{Keywords:}

BNST

Corticotropin-releasing factor

Glutamate

Nitric oxide

Blood pressure

Heart rate

\begin{abstract}
A B S T R A C T
The aims of the present study were to assess an interaction of corticotropin-releasing factor (CRF) neurotransmission within the bed nucleus of the stria terminalis (BNST) with local nitrergic signaling, as well as to investigate an involvement of activation of local NMDA glutamate receptor and nitric oxide (NO) signaling in control of cardiovascular responses to acute restraint stress by BNST CRF neurotransmission in rats. We observed that CRF microinjection into the BNST increased local NO release during restraint stress. Furthermore, bilateral microinjection of CRF into the BNST enhanced both the arterial pressure and heart rate increases evoked by restraint stress, but without affecting the sympathetically-mediated cutaneous vasoconstriction. The facilitation of both pressor and tachycardiac responses to restraint stress evoked by BNST treatment with CRF were completely inhibited by local pretreatment with either the selective NMDA glutamate receptor antagonist LY235959, the selective neuronal nitric oxide synthase (nNOS) inhibitor N $\omega$-Propyl-L-arginine (NPLA), the soluble guanylate cyclase (sGC) inhibitor $1 \mathrm{H}-[1,2,4]$ Oxadiazolo[4,3-a]quinoxalin-1-one (ODQ) or the protein kinase G (PKG) inhibitor KT5823. Taken together, these results provide evidence that BNST CRF neurotransmission facilitates local NMDA-mediated glutamatergic neurotransmission and activates nitrergic signaling, and this pathway is involved in control of cardiovascular responses to stress.
\end{abstract}

\section{Introduction}

A coordinated and complex set of physiological changes, including cardiovascular and endocrine changes, occurs during aversive stimuli for maintenance of homeostasis (Crestani, 2016; Sterling, 2012; UlrichLai and Herman, 2009). These responses are triggered by overlapping limbic circuits in the central nervous system (Dampney, 2015; Myers, 2017; Ulrich-Lai and Herman, 2009). The bed nucleus of the stria terminalis (BNST) is a limbic structure located in the prosencephalon in which has been recognized as a critical component of neural substrates of responses to aversive stimuli (Crestani et al., 2013; Myers, 2017; Ulrich-Lai and Herman, 2009). Indeed, the BNST is implicated in cardiovascular, neuroendocrine and behavioral responses to stress (Crestani et al., 2013; Davis et al., 2010). However, the local neurochemical mechanisms mediating the BNST control of stress responses are not completely understood.

The corticotropin-releasing factor (CRF) system has emerged as a crucial local neurochemical mechanism involved in BNST-mediated control of both behavioral and physiological responses evoked by aversive threats (Crestani et al., 2013; Daniel and Rainnie, 2016; Davis et al., 2010). Specifically regarding the cardiovascular responses, Nijsen et al. (2001) first reported that BNST treatment with a nonselective CRF receptor antagonist enhanced the heart rate (HR) increase evoked by contextual fear conditioning, thus indicating an inhibitory influence of BNST CRF neurotransmission on cardiac responses to conditioned stressors. Further, results from our group evidenced that microinjection of selective antagonists of either $\mathrm{CRF}_{1}$ or $\mathrm{CRF}_{2}$ receptor into the BNST dose-dependently decreased the arterial pressure, HR and the sympathetically-mediated cutaneous vasoconstriction evoked by restraint stress (Oliveira et al., 2015). These results provided evidence of a prominent role of CRF neurotransmission in BNST control of cardiovascular responses to aversive stimuli.

Interaction between CRF and glutamatergic neurotransmissions within the BNST has been described (Silberman and Winder, 2013). This interaction was evidenced by demonstration that CRF application onto BNST in vitro increased frequency, but not amplitude, of spontaneous excitatory postsynaptic currents (sEPSC) (Kash et al., 2008; Silberman et al., 2013). Pretreatment with a selective $\mathrm{CRF}_{1}$ receptor antagonist, but not with a selective $\mathrm{CRF}_{2}$ receptor antagonist, inhibited the ability of CRF to increase frequency of sEPSC (Kash et al., 2008).

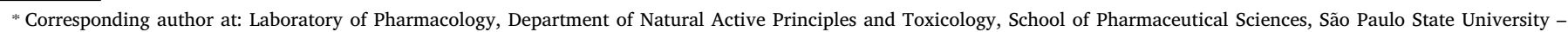
UNESP, Rodovia Araraquara KM 01 (Campus Universitário), 14800-903, Araraquara, SP, Brazil.

E-mail address: crestani@fcfar.unesp.br (C.C. Crestani).
} 
Taken together, these results indicated that CRF acts presynaptically via $\mathrm{CRF}_{1}$ receptor to increase glutamatergic neurotransmission within the BNST (Silberman and Winder, 2013).

Activation of $N$-methyl-D-aspartate (NMDA) glutamate receptor in post-synaptic neurons increases $\mathrm{Ca}^{2+}$ influx, which in turn activates the neuronal isoform of the enzyme nitric oxide synthase (nNOS), thus resulting in nitric oxide (NO) synthesis (Garthwaite, 2008; Prast and Philippu, 2001). Despite reports of presence of neurons capable of synthesizing NO within the BNST (Guimaraes et al., 2005; Vincent and Kimura, 1992), as well as identification of CRF action facilitating glutamatergic neurotransmission in this structure (Silberman and Winder, 2013), an interaction between CRF and nitrergic neurotransmission has never been reported. Furthermore, a possible role of CRF-glutamate interaction in mediating BNST control of responses during aversive threats has never been evaluated.

Neurons synthesizing NO within the BNST are activated by aversive stimuli (Guimaraes et al., 2005), and systemic treatment with nNOS inhibitors decreases stress-evoked activation of BNST neurons (Silva et al., 2012), thus indicating a recruitment of BNST nitrergic neurotransmission during aversive threats. Furthermore, a recent study from our group reported that BNST treatment with the selective NMDA glutamate receptor LY235959 decreased the HR increase to restraint stress (Adami et al., 2017), an effect similar to that observed following BNST treatment with a $\mathrm{CRF}_{1}$ receptor antagonist (Oliveira et al., 2015). Based on these pieces of evidence, this study aimed to evaluate the hypothesis that the facilitatory influence of BNST CRF neurotransmission in cardiovascular responses evoked by an acute session of restraint stress in rats is mediated by activation of local NMDA glutamate receptor and nNOS, as well as of signaling mechanisms related to NO effects such as soluble guanylate cyclase (sGC) and protein kinase $\mathrm{G}$ (PKG) (Garthwaite, 2008; Hofmann et al., 2006).

\section{Materials and methods}

\subsection{Animals}

Ninety-seven male Wistar rats weighting about $250 \mathrm{~g}$ (60-days-old) were used. Thirteen of these animals were excluded of the study because the microinjection sites reached structures surrounding the BNST. All animals were supplied by the breeding facility of the UNESP (Botucatu, SP, Brazil), and were housed in collective plastic cages (4 animals/cage) in a temperature-controlled room at $24^{\circ} \mathrm{C}$ in the Animal Facility of the Laboratory of Pharmacology/School of Pharmaceutical Sciences-UNESP. They were kept under a 12:12 h light-dark cycle (lights on between 7:00 a.m. and 7:00 p.m.) with free access to water and standard rat chow. Housing conditions and experimental procedures were approved by local Ethical Committee for Use of Animals (School of Pharmaceutical Science/UNESP) (approval \# 34/2015), which complies with Brazilian and international guidelines for animal use and welfare.

\subsection{Surgical preparation}

At least one week after the arrival of the animals in the laboratory, and five days before the experiment, the animals were anesthetized with tribromoethanol $(250 \mathrm{mg} / \mathrm{kg}$, i.p.), scalp was anesthetized with $2 \%$ lidocaine, and the skull was exposed. Then, using a stereotaxic apparatus (Stoelting, Wood Dale, Illinois, USA), stainless-steel cannulas (26G, $12 \mathrm{~mm}$-long) were bilaterally implanted into the BNST. Stereotaxic coordinates were: antero-posterior $=+7.8 \mathrm{~mm}$ from interaural; lateral $=+4.0 \mathrm{~mm}$ from the medial suture, ventral $=-5.8 \mathrm{~mm}$ from the skull, with a lateral inclination of $23^{\circ}$ (Paxinos and Watson, 1997). Dental cement was used to fix cannulas to the skull. After surgery, the rats were treated with a poly-antibiotic containing streptomycins and penicillins to prevent infection $(560 \mathrm{mg} / \mathrm{ml} / \mathrm{kg}$, i.m.), and the non-steroidal anti-inflammatory flunixin meglumine for post- operation analgesia $(0.5 \mathrm{mg} / \mathrm{ml} / \mathrm{kg}$, s.c. $)$.

One day before the trial, rats were again anesthetized with tribromoethanol $(250 \mathrm{mg} / \mathrm{kg}$, i.p.) and a polyethylene cannula (a $4 \mathrm{~cm}$ segment of PE-10 bound to a $13 \mathrm{~cm}$ segment of PE-50) (Clay Adams, Parsippany, NJ, USA) was implanted into the abdominal aorta via the femoral artery for cardiovascular recording. The catheter was tunneled under the skin and exteriorized on the animal's dorsum. After surgery, the non-steroidal anti-inflammatory flunixin meglumine was administered for post-operation analgesia $(0.5 \mathrm{mg} / \mathrm{ml} / \mathrm{kg}$, s.c.). The animals were kept in individual cages during the post-operative period and cardiovascular recording.

\subsection{Blood pressure and heart rate recording}

The cannula inserted into the femoral artery was connected to a pressure transducer (DPT100, Utah Medical Products Inc., Midvale, UT, USA). Pulsatile arterial pressure (PAP) was recorded using an amplifier (Bridge Amp, ML224, ADInstruments, Australia) and an acquisition board (PowerLab 4/30, ML866/P, ADInstruments, NSW, Australia) connected to a personal computer. Mean arterial pressure (MAP) and HR values were obtained from the PAP recording.

\subsection{Tail skin temperature measurement}

The recording of the tail skin temperature was made using an infrared digital thermographic camera (IRI4010, InfraRed Integrates Systems Ltd, Northampton, UK). The analysis was performed using a software for thermographic analysis, and temperature was represented by color intensity variations (Busnardo et al., 2013; Vianna and Carrive, 2005). For image analysis, the temperature was measured at five points along the animal's tail, and the mean was calculated for each recording (Busnardo et al., 2013; Oliveira et al., 2015).

\subsection{Drug microinjection into the BNST}

The needles (33G, Small Parts, Miami Lakes, FL, USA) used for microinjection into the BNST were $1 \mathrm{~mm}$ longer than the guide cannulas and were connected to a $2 \mu \mathrm{L}$ syringe (7002-KH, Hamilton Co., Reno, NV, USA) via a PE-10 tubing (Clay Adams, Parsippany, NJ, USA). Intra-cerebral microinjections were performed within a $5 \mathrm{~s}$ period, and the needle was left in the guide cannula for $1 \mathrm{~min}$ after the microinjection before being removed. Microinjection was performed without restraining the animals, and drugs were administrated in a final volume of $100 \mathrm{~nL}$ per side (Crestani et al., 2009; Oliveira et al., 2015). Photomicrograph of a coronal brain section depicting bilateral microinjection sites in the BNST of a representative animal is presented in Fig. S1.

\subsection{Restraint stress}

The acute restraint stress consisted of introducing the animals into plastic cylindrical tubes (diameter $=6.5 \mathrm{~cm}$, length $=15 \mathrm{~cm}$ ), which were ventilated by $1 / 2$ inch holes that comprised approximately $20 \%$ of the tube. The animals were maintained for a period of $30 \mathrm{~min}$ into the restraint tube (Crestani et al., 2010; Oliveira et al., 2015). Each animal was submitted to only one session of stress in order to avoid habituation.

\subsection{Drugs and solutions}

Corticotropin-releasing factor (CRF) (TOCRIS, Westwoods Business, Park Ellisville, MO, USA; cat. \# 1151), LY235959 (selective NMDA glutamate receptor antagonist) (TOCRIS; cat. \# 1019), $N^{\omega}$-Propyl-L-arginine hydrochloride (NPLA) (selective nNOS inhibitor) (TOCRIS; cat. \# 1200), tribromoethanol (Sigma-Aldrich, St Louis, Missouri, USA; cat. \# T48402) and urethane (Sigma-Aldrich; cat. \# U2500) were dissolved in saline $(\mathrm{NaCl} 0.9 \%)$. 1H-[1,2,4] Oxadiazolo[4,3-a]quinoxalin-1-one 
(ODQ) (inhibitor of SGC) (TOCRIS, cat. \# 0880) and KT5823 (inhibitor of PKG) (TOCRIS, cat. \# 1289) were dissolved in a solution of saline containing $20 \%$ of DMSO (DMSO 20\%). Flunixin meglumine (Banamine, Schering Plough, Cotia, SP, Brazil) and the polyantibiotic preparation of streptomycins and penicillins (Pentabiotico, Fort Dodge, Campinas, SP, Brazil) were used as provided.

\subsection{Measurement of nitrogen oxides}

The animals were decapitated, and then their brains were quickly removed and frozen in isopentane on dry ice. Following this procedure, the brain was stored at $-80^{\circ} \mathrm{C}$ until dissection of BNST. For microdissection of BNST, frozen brains were serially sliced at $50 \mu \mathrm{m}$ in the coronal plane until the BNST region in a cryostat (CM1900, Leica, Wetzlar, Germany) kept at $-20^{\circ} \mathrm{C}$. Microdissection of the BNST was performed from the brain fixed in the cryostat using a blunt 14-gauge needle. The coordinate for dissection was approximately from $+0.20 \mathrm{~mm}$ to $-0.80 \mathrm{~mm}$ related to bregma, according to Paxinos and Watson (1997). Photomicrograph of a coronal brain section depicting a representative tissue punch of the BNST is presented in Fig. S2.

The quantification of $\mathrm{NO}_{2}$ and $\mathrm{NO}_{3}$ (NOx) (spontaneous oxidation products) were utilized as an indirect measurement of NO production (Camargo et al., 2013). For this, the samples were homogenized into lysis buffer (Tris- $\mathrm{HCl} 20 \mathrm{mM} \mathrm{pH} \mathrm{7.6;} \mathrm{NaCl} 137 \mathrm{mM}, 10 \%$ glycerol) containing proteases and phosphatases inhibitors. The NOx levels were measured from homogenized samples accordingly to methodology previously described (Camargo et al., 2013). Briefly, for conversion of $\mathrm{NO}_{3}$ into $\mathrm{NO}_{2}$, homogenized samples were incubated overnight at $37^{\circ} \mathrm{C}$ with solution containing nitrate reductase (\#N7265, Sigma-Aldrich) and NADPH (\#33461, Sigma-Aldrich) $(0.4 \mathrm{U} / \mathrm{ml}$ and $1 \mathrm{mg} / \mathrm{ml}$, respectably, diluted in $\mathrm{KH}_{2} \mathrm{PO}_{4}$ buffer $1 \mathrm{M} \mathrm{pH}$ 7.4). Then, $\mathrm{NO}_{2}$ level was determined by adding $15 \mu \mathrm{L}$ of Griess reagent (1\% sulphanilamide with $5 \%$ phosphoric acid in distilled water $+0.1 \% N$-(1-naphthyl) ethylenediamine dihydrochloride in distilled water, v/v). After $10 \mathrm{~min}$ of incubation at room temperature, absorbance was read at $540 \mathrm{~nm}$, and the results were calculated based on a standard curve of sodium nitrite $\left(\mathrm{NaNO}_{2}\right)$ (Sigma-Aldrich, St. Louis, MO, USA). The total content of protein in each sample was measured using a Bio-Rad ${ }^{\star}$ kit (DC ${ }^{\circ}$ protein assay). Measurements of nitrite were performed in duplicate, and results were expressed as $\mu \mathrm{M} \mathrm{NOx} / \mu \mathrm{g}$ protein.

\subsection{Experimental protocols}

Rats were brought to the experimental room in their own cage. Animals were allowed at least $60 \mathrm{~min}$ to adapt to experimental room conditions, such as sound and illumination, before starting the experiment. The experimental room was temperature controlled $\left(24^{\circ} \mathrm{C}\right)$ and acoustically isolated from other rooms.

\subsubsection{Effect of CRF microinjection into the BNST on local NOx levels} during acute restraint stress

This protocol aimed to investigate whether CRF activates NMDA/ nNOS pathway within BNST during acute restraint stress, thus resulting in increased formation of local NO. For this, animals were treated with either vehicle (saline, $100 \mathrm{~nL} / \mathrm{side})$ or CRF $(0.07 \mathrm{nmol} / 100 \mathrm{~nL} / \mathrm{side})$, and $5 \mathrm{~min}$ later were submitted to a $30 \mathrm{~min}$ session of restraint stress. Immediately after restraint, the animals were euthanized and the brain was obtained for evaluation of NOx levels in the BNST.

\subsubsection{Involvement of local NMDA/nNOS/sGC/PKG signaling in control of} cardiovascular responses to restraint stress by CRF into the BNST

The aim of this protocol was to investigate the involvement of local NMDA glutamate receptor, nNOS, sGC and PKG in control of cardiovascular responses to acute restraint stress by CRF into the BNST. For this, independent sets of rats were pretreated into the BNST with either the selective NMDA receptor antagonist LY235959 (0.5 nmol/100 nL/ side), the selective nNOS inhibitor NPLA $(0.2 \mathrm{nmol} / 100 \mathrm{~nL} / \mathrm{side})$, the sGC inhibitor ODQ $(0.5 \mathrm{nmol} / 100 \mathrm{~nL} /$ side $)$, the selective PKG inhibitor KT5823 $(0.01 \mathrm{nmol} / 100 \mathrm{~nL} / \mathrm{side}$ ) or vehicle (saline or DMSO $20 \%$, $100 \mathrm{~nL} /$ side) (Alves et al., 2009; Busnardo et al., 2010a; Hott et al., 2017). Five minutes later the animals received either vehicle (saline, $100 \mathrm{~nL} /$ side) or CRF $(0.07 \mathrm{nmol} / 100 \mathrm{~nL} /$ side) into the BNST (Oliveira et al., 2015).

Five minutes after the second pharmacological treatment of the BNST, animals in all experimental groups underwent a 30-min session of restraint stress. Blood pressure and heart rate recordings started at least $30 \mathrm{~min}$ before the onset of the stress session, and were performed throughout the restraint stress period. Tail skin temperature was measured at 10, 5 and $0 \mathrm{~min}$ before the restraint, and every $5 \mathrm{~min}$ during the stress session.

\subsection{Histological determination of the microinjection sites}

At the end of each experiment, animals were anesthetized with urethane $(1.2 \mathrm{~g} / \mathrm{kg}$, i.p.), and $1 \%$ Evan's blue dye was microinjected into the brain at the same volume of drug injection (i.e., $100 \mathrm{~nL} / \mathrm{side}$ ) as a marker of microinjection site. Then, the brains were removed and post-fixed in $10 \%$ formalin solution for at least $48 \mathrm{~h}$ at $4{ }^{\circ} \mathrm{C}$. Afterwards, serial $40 \mu \mathrm{m}$ thick sections of the BNST region were cut using a cryostat (CM1900, Leica, Wetzlar, Germany). The sites of injection were analyzed according to Paxinos and Watson (1997).

\subsection{Statistical analysis}

Data were expressed by mean \pm standard error of the mean (SEM). NOx levels in the BNST were compared using Student's $t$-test. The basal values of MAP, HR and tail skin temperature were compared using oneway ANOVA. Restraint-evoked cardiovascular changes were obtained for each measure by calculating the difference between the values recorded during the restraint stress and the baseline value obtained by the mean of points recorded across the $10 \mathrm{~min}$ before the restraint onset. The time-course curves of MAP, HR and tail skin temperature changes were analyzed using two-way ANOVA, with treatment as main factor and time as repeated measurement. For identification of specific differences between the experimental groups (post hoc analysis), the mean of all points across the restraint stress period in the time-course curves (i.e., from time 0-30) was calculated, and these values were compared across the groups using one-way ANOVA followed by Bonferroni's post hoc test. Results of statistical tests with $\mathrm{P}<0.05$ were considered significant.

\section{Results}

3.1. Effect of CRF microinjection into the BNST on local NOx levels during acute restraint stress

Bilateral microinjection of $\mathrm{CRF}(0.07 \mathrm{nmol} / 100 \mathrm{~nL} /$ side, $\mathrm{n}=8)$ into the BNST increased the local NOx levels following exposure to acute restraint stress $(\mathrm{t}=2.2, \mathrm{P}<0.04)$, when compared with vehicletreated animals (100 $\mathrm{nL} /$ side, $\mathrm{n}=7$ ) (Fig. 1).

3.2. Involvement of local NMDA/nNOS/sGC/PKG signaling in control of cardiovascular responses to restraint stress by BNST CRF neurotransmission

NMDA receptor - Bilateral microinjections of the selective NMDA glutamate receptor antagonist LY235959 $(0.5 \mathrm{nmol} / 100 \mathrm{~nL} /$ side $)$ and/ or CRF $(0.07 \mathrm{nmol} / 100 \mathrm{~nL} / \mathrm{side})$ into the BNST did not affect baseline values of either MAP, HR or tail skin temperature (Table 1) However, acute restraint stress caused a sustained increase on both MAP (time: $\left.\mathrm{F}_{(19,399)}=12, \mathrm{P}<0.0001\right)$ and HR (time: $\left.\mathrm{F}_{(19,399)}=8, \mathrm{P}<0.0001\right)$, and decreased the tail skin temperature (time: $\mathrm{F}_{(8,160)}=12$, $\mathrm{P}<0.0001$ ) (Fig. 2). Besides, analysis indicated an effect of BNST 


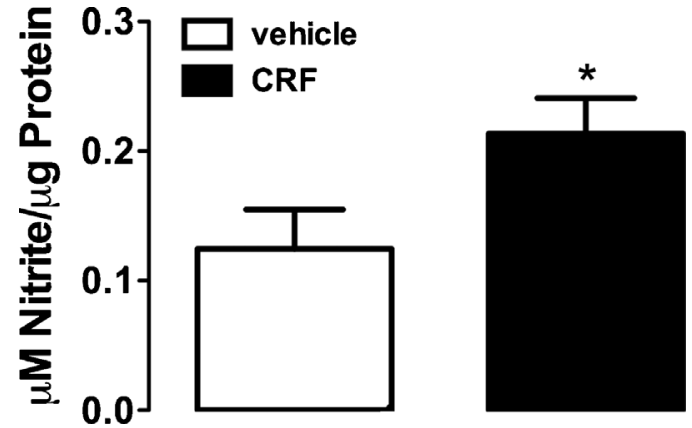

Fig. 1. (Top) Levels of NOx in the bed nucleus of the stria terminalis (BNST) following exposure to a 30-min session of restraint stress in animals that received bilateral microinjection of vehicle (saline, $100 \mathrm{~nL} / \mathrm{side}, \mathrm{n}=7)$ or CRF $(0.07 \mathrm{nmol} / 100 \mathrm{~nL} / \mathrm{side}, \mathrm{n}=8)$ into the BNST. Columns represent the mean and bars the S.E.M. ${ }^{*} \mathrm{P}<0.05$, Student's $t$ test.

Table 1

Basal parameters of mean arterial pressure (MAP), heart rate (HR) and tail skin temperature (T) after pharmacological treatments of the BNST.

\begin{tabular}{|c|c|c|c|c|}
\hline Groups & MAP (mmHg) & HR (bpm) & $\mathrm{T}\left({ }^{\circ} \mathrm{C}\right)$ & $\mathrm{n}$ \\
\hline VEH + VEH & $111 \pm 2$ & $337 \pm 22$ & $27.8 \pm 1$ & 6 \\
\hline $\mathrm{LY}+\mathrm{VEH}$ & $104 \pm 3$ & $383 \pm 21$ & $28.9 \pm 2$ & 6 \\
\hline $\mathrm{VEH}+\mathrm{CRF}$ & $106 \pm 4$ & $363 \pm 9$ & $26.6 \pm 1$ & 6 \\
\hline \multirow{3}{*}{$L Y+C R F$} & $119 \pm 4$ & $394 \pm 19$ & $26.9 \pm 1$ & 6 \\
\hline & $F_{(3,23)}=2.9$ & $F_{(3,23)}=1.8$ & $F_{(3,23)}=0.7$ & \\
\hline & $P>0.05$ & $P>0.05$ & $P>0.05$ & \\
\hline $\mathrm{VEH}+\mathrm{VEH}$ & $111 \pm 2$ & $337 \pm 22$ & $27.8 \pm 1$ & 6 \\
\hline NPLA + VEH & $107 \pm 5$ & $375 \pm 9$ & $28.7 \pm 1$ & 6 \\
\hline VEH + CRF & $106 \pm 4$ & $363 \pm 9$ & $26.5 \pm 1$ & 6 \\
\hline \multirow[t]{3}{*}{ NPLA + CRF } & $107 \pm 3$ & $361 \pm 28$ & $26.7 \pm 1$ & 6 \\
\hline & $F_{(3,23)}=0.3$ & $F_{(3,23)}=0.7$ & $F_{(3,23)}=1.0$ & \\
\hline & $P>0.05$ & $P>0.05$ & $P>0.05$ & \\
\hline DMSO + SAL & $114 \pm 4$ & $379 \pm 15$ & $29.1 \pm 1$ & 6 \\
\hline ODQ + SAL & $111 \pm 3$ & $365 \pm 35$ & $27.0 \pm 0.4$ & 6 \\
\hline $\mathrm{DMSO}+\mathrm{CRF}$ & $105 \pm 3$ & $366 \pm 15$ & $28.9 \pm 0.3$ & 6 \\
\hline \multirow[t]{3}{*}{$\mathrm{ODQ}+\mathrm{CRF}$} & $109 \pm 2$ & $387 \pm 15$ & $27.8 \pm 0.4$ & 6 \\
\hline & $F_{(3,23)}=1.5$ & $F_{(3,23)}=0.2$ & $F_{(3,23)}=2.7$ & \\
\hline & $P>0.05$ & $P>0.05$ & $P>0.05$ & \\
\hline DMSO + SAL & $114 \pm 4$ & $379 \pm 15$ & $29.1 \pm 1$ & 6 \\
\hline $\mathrm{KT}+\mathrm{SAL}$ & $108 \pm 4$ & $400 \pm 20$ & $29.6 \pm 0.6$ & 5 \\
\hline $\mathrm{DMSO}+\mathrm{CRF}$ & $105 \pm 3$ & $366 \pm 15$ & $28.8 \pm 0.4$ & 6 \\
\hline \multirow[t]{3}{*}{$\mathrm{KT}+\mathrm{CRF}$} & $105 \pm 2$ & $372 \pm 16$ & $28.8 \pm 0.5$ & 5 \\
\hline & $F_{(3,20)}=1.6$ & $F_{(3,20)}=0.4$ & $F_{(3,20)}=0.3$ & \\
\hline & $P>0.05$ & $P>0.05$ & $P>0.05$ & \\
\hline
\end{tabular}

pharmacological treatments on MAP $\left(\mathrm{F}_{(3,20)}=8, \mathrm{P}<0.0001\right)$ and HR $\left(\mathrm{F}_{(3,20)}=12, \mathrm{P}<0.0001\right)$ responses to restraint stress, but without affecting the drop on tail skin temperature $\left(\mathrm{F}_{(3,20)}=0.6, \mathrm{P}<0.05\right)$ (Fig. 2). Nevertheless, analysis did not indicate a significant stress $\mathrm{x}$ time interaction for either MAP $\left(\mathrm{F}_{(57,399)}=0.6, \mathrm{P}>0.05\right)$, HR $\left(\mathrm{F}_{(57,399)}=0.5, \mathrm{P}>0.05\right)$ or tail skin temperature $\left(\mathrm{F}_{(24,160)}=0.2\right.$, $\mathrm{P}>0.05$ ). Post hoc analysis revealed that CRF (veh + CRF group) enhanced the increase of both MAP $(P<0.01)$ and HR $(P<0.05)$. CRF effects on both MAP $(\mathrm{P}>0.05)$ and HR $(\mathrm{P}>0.05)$ responses to restraint stress were inhibited in animals pretreated with LY235959 into the BNST (Fig. 2). Fig. 2 presents diagrammatic representations showing microinjection sites into the BNST of all animals used in this protocol.

nNOS - Bilateral microinjections of the selective nNOS inhibitor NPLA $(0.2 \mathrm{nmol} / 100 \mathrm{~nL} / \mathrm{side})$ and/or CRF $(0.07 \mathrm{nmol} / 100 \mathrm{~nL} / \mathrm{side})$ into the BNST did not affect baseline values of either MAP, HR or tail skin temperature (Table 1). However, acute restraint stress caused a sustained increase on both MAP (time: $\mathrm{F}_{(19,399)}=34, \mathrm{P}<0.0001$ ) and HR (time: $F_{(19,399)}=14, P<0.0001$ ), and evoked a drop on tail skin temperature (time: $\mathrm{F}_{(8,160)}=9, \mathrm{P}<0.0001$ ) (Fig. 3). Besides, analysis indicated an effect of pharmacological treatments on restraint-evoked increase of $\mathrm{MAP}\left(\mathrm{F}_{(3,20)}=11, \mathrm{P}<0.0001\right)$ and $\mathrm{HR}\left(\mathrm{F}_{(3,20)}=15\right.$, $\mathrm{P}<0.001$ ), but without affecting the drop in skin temperature $\left(\mathrm{F}_{(3,20)}=0.9, \mathrm{P}>0.05\right)$ (Fig. 3). Analysis of $\operatorname{MAP}\left(\mathrm{F}_{(57,399)}=1\right.$, $\mathrm{P}>0.05), \mathrm{HR}\left(\mathrm{F}_{(57,399)}=0.9, \mathrm{P}>0.05\right)$ and tail skin temperature $\left(\mathrm{F}_{(24,160)}=0.3, \mathrm{P}>0.05\right)$ did not indicate a significant stress $\mathrm{x}$ time interaction. Post hoc analysis revealed that CRF (veh + CRF group) enhanced the increase of both MAP $(P<0.006)$ and HR $(P<0.02)$. CRF effects on both pressor $(\mathrm{P}>0.05)$ and tachycardiac $(\mathrm{P}>0.05)$ responses to restraint were inhibited in animals pretreated with NPLA into the BNST (Fig. 3). Fig. 3 presents diagrammatic representations showing microinjection sites into the BNST of all animals used in this protocol.

$s G C$ - Bilateral microinjections of the selective sGC inhibitor ODQ $(0.5 \mathrm{nmol} / 100 \mathrm{~nL} / \mathrm{side})$ and/or CRF $(0.07 \mathrm{nmol} / 100 \mathrm{~nL} / \mathrm{side})$ into the BNST did not affect baseline values of either MAP, HR or tail skin temperature (Table 1). However, restraint stress caused an sustained increase on both MAP (time: $\mathrm{F}_{(19,399)}=15, \mathrm{P}<0.0001$ ) and HR (time: $\left.\mathrm{F}_{(19,399)}=3, \mathrm{P}<0.0001\right)$, and decreased the tail skin temperature (time: $\mathrm{F}_{(8,160)}=30, \mathrm{P}<0.0001$ ) (Fig. 4). Besides, analysis of MAP $\left(\mathrm{F}_{(3,20)}=26, \mathrm{P}<0.0001\right)$ and $\mathrm{HR}\left(\mathrm{F}_{(3,20)}=4, \mathrm{P}<0.007\right)$, but not of tail skin temperature $\left(\mathrm{F}_{(3,20)}=0.6, \mathrm{P}>0.05\right)$, indicated an effect of pharmacological treatments of the BNST (Fig. 4). Nevertheless, analysis did not indicate a significant stress $\mathrm{x}$ time interaction for MAP $\left(\mathrm{F}_{(57,399)}=0.7, \mathrm{P}>0.05\right), \mathrm{HR}\left(\mathrm{F}_{(57,399)}=0.2, \mathrm{P}>0.05\right)$ and tail skin temperature $\left(\mathrm{F}_{(24,160)}=0.4, \mathrm{P}>0.05\right)$. Post hoc analysis revealed that CRF (veh + CRF group) enhanced the restraint-evoked increase of MAP $(\mathrm{P}<0.05)$ (Fig. 4). The effect of CRF increasing restraint-evoked pressor response was inhibited when animals were pretreated with ODQ ( $\mathrm{P}>0.05$ ) (Fig. 4). Fig. 4 presents diagrammatic representations showing microinjection sites into the BNST of all animals used in this protocol.

PKG - Bilateral microinjections of the selective PKG inhibitor KT5823 ( $0.01 \mathrm{nmol} / 100 \mathrm{~nL} / \mathrm{side})$ and/or CRF $(0.07 \mathrm{nmol} / 100 \mathrm{~nL} / \mathrm{side})$ into the BNST did not affect baseline values of either MAP, HR or tail skin temperature (Table 1 ). Nevertheless, restraint stress caused a sustained increase on both MAP (time: $\mathrm{F}_{(19,342)}=13, \mathrm{P}<0.0001$ ) and HR (time: $\mathrm{F}_{(19,342)}=7, \mathrm{P}<0.0001$ ), and decreased the tail skin temperature (time: $\mathrm{F}_{(8,144)}=28, \mathrm{P}<0.0001$ ) (Fig. 5). Besides, analysis of $\operatorname{MAP}\left(\mathrm{F}_{(3,18)}=20, \mathrm{P}<0.0001\right), \mathrm{HR}\left(\mathrm{F}_{(3,18)}=7, \mathrm{P}<0.0002\right)$ and tail skin temperature $\left(\mathrm{F}_{(3,18)}=18, \mathrm{P}<0.0001\right)$ indicated effect of BNST pharmacological treatments (Fig. 5). However, analysis did not indicate a significant stress $\mathrm{x}$ time interaction for $\mathrm{MAP}\left(\mathrm{F}_{(57,342)}=0.9\right.$, $\mathrm{P}>0.05), \mathrm{HR}\left(\mathrm{F}_{(57,342)}=0.4, \mathrm{P}>0.05\right)$ and tail skin temperature $\left(F_{(24,144)}=0.6, P>0.05\right)$. Post hoc analysis revealed that CRF (veh $+\mathrm{CRF}$ group) increased the restraint-evoked increase of MAP $(P<0.05)$ and HR $(P<0.05)$. CRF effects on restraint-evoked pressor $(\mathrm{P}>0.05)$ and tachycardiac $(\mathrm{P}>0.05)$ responses were inhibited in animals pretreated with KT5823 into the BNST (Fig. 5). Furthermore, the drop on tail skin temperature evoked by restraint was decreased in animals subjected to combined treatment with KT5823 plus CRF (KT + CRF group) $(\mathrm{P}<0.04)$ (Fig. 5). Fig. 5 presents diagrammatic representations showing microinjection sites into the BNST of all animals used in the present study.

Microinjection of the antagonist/inhibitors (i.e., LY235959, NPLA, ODQ or KT5328) and/or CRF into structures surrounding the BNST did not affect the restraint-evoked cardiovascular responses (data not shown).

\section{Discussion}

The present study provides the first evidence of an interaction between CRF and nitrergic neurotransmissions within the BNST. Furthermore, this study first describes that the modulation of cardiovascular responses to stress by CRF within the BNST is mediated by activation of local glutamatergic and nitrergic neurotransmissions. 

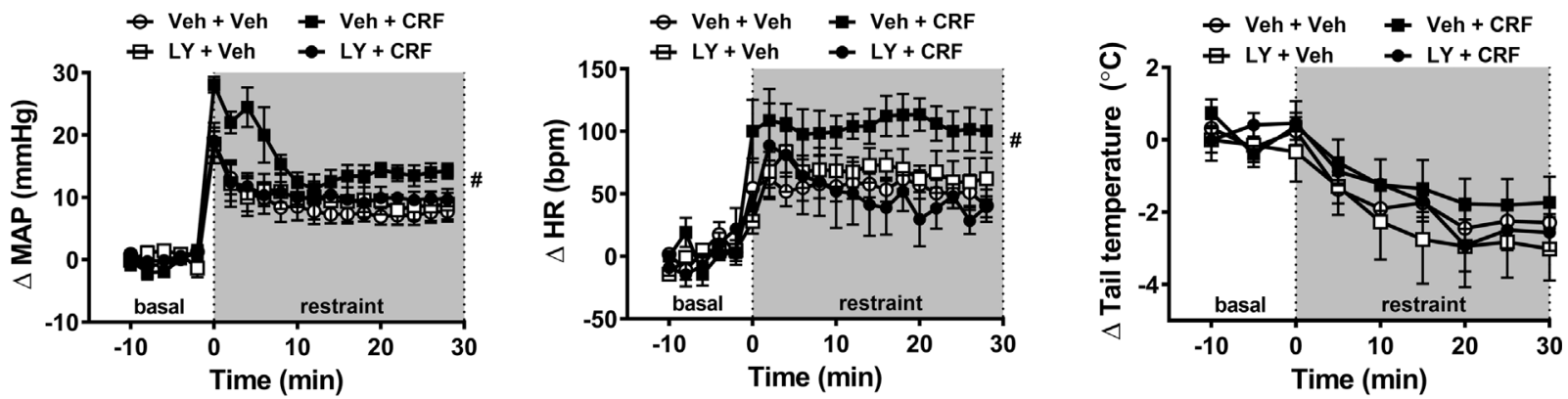

IA $8.74 \mathrm{~mm}$
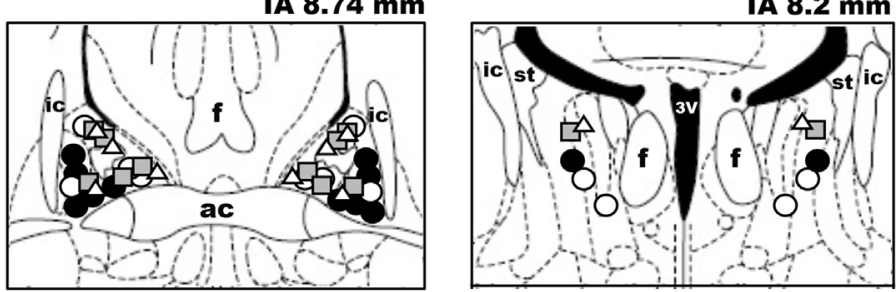

$O \mathrm{Veh}+\mathrm{Veh} \square \mathrm{Veh}+\mathrm{CRF}$

- LY + Veh $\triangle \mathrm{LY}+\mathrm{CRF}$

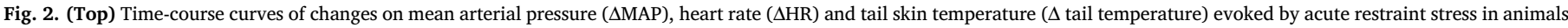

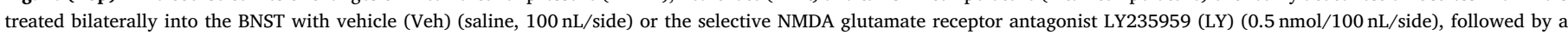

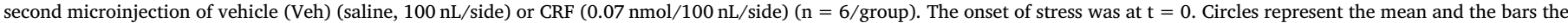

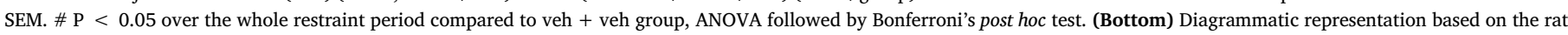



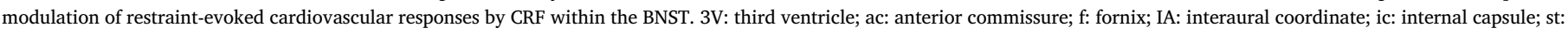
stria terminalis.

Indeed, we observed that CRF microinjection into the BNST increased local NO formation during restraint stress, as evidenced by increased local NOx levels. Furthermore, local BNST pretreatment with a selective NMDA receptor antagonist, as well as with inhibitors of either the nNOS, sGC or PKG, inhibited the enhance of restraint-evoked pressor and tachycardiac responses observed following microinjection of CRF into the BNST.

The CRF neuropeptide family includes the CRF and other three peptides designated urocortin 1 (Ucn1), urocortin 2 (Ucn2) and urocortin 3 (Ucn3) (Bale and Vale, 2004; Hauger et al., 2003). Actions of $\mathrm{CRF}$ and the related peptides are mediated by activation of two receptors, $\mathrm{CRF}_{1}$ and $\mathrm{CRF}_{2}$ receptors, as well as of one binding-protein of
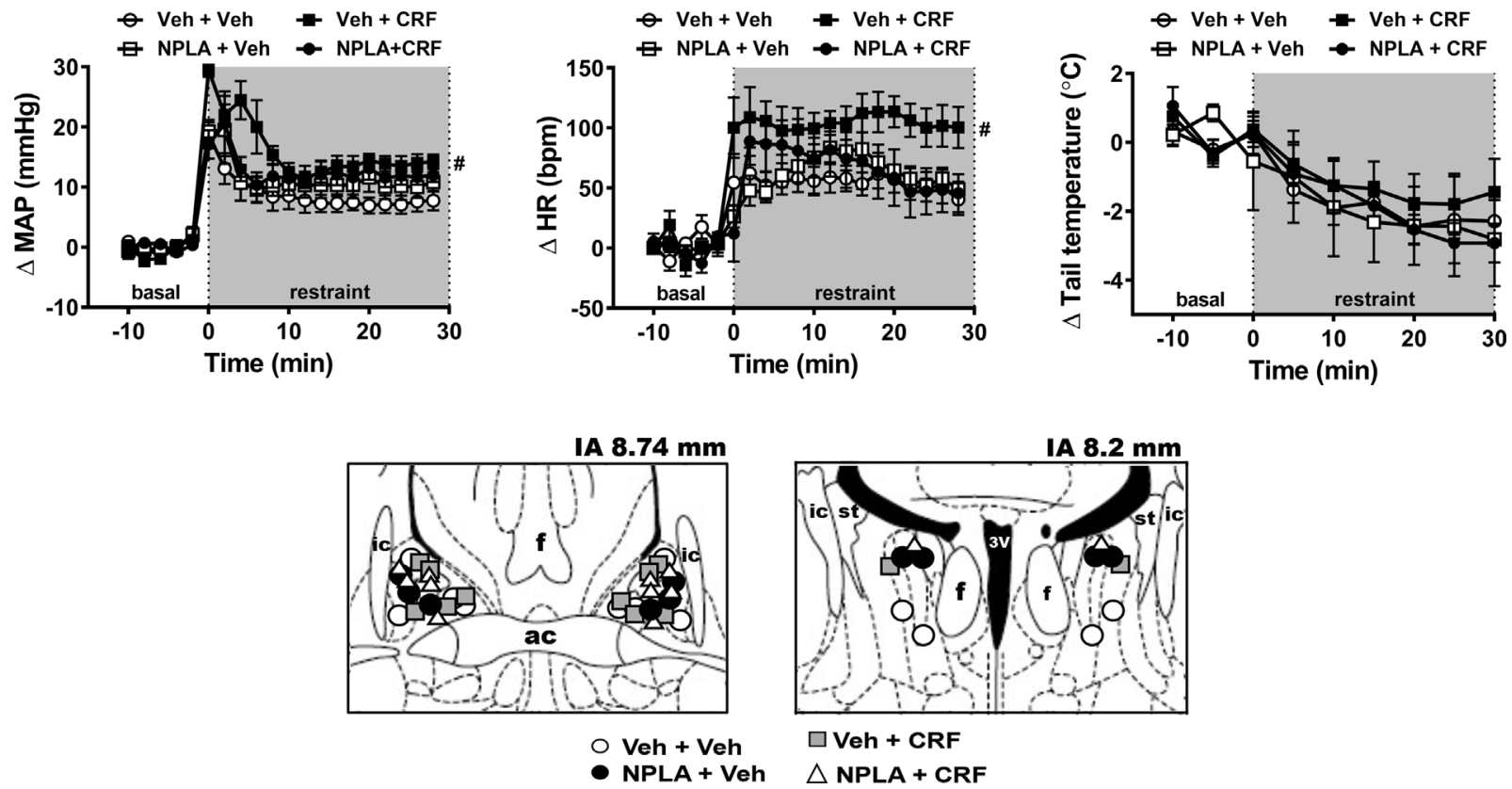

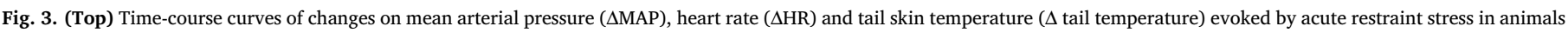

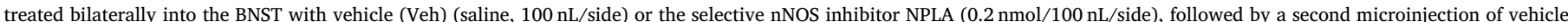



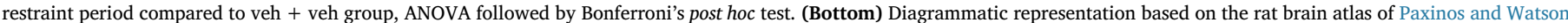


responses by CRF within the BNST. 3V: third ventricle; ac: anterior commissure; f: fornix; IA: interaural coordinate; ic: internal capsule; st: stria terminalis. 

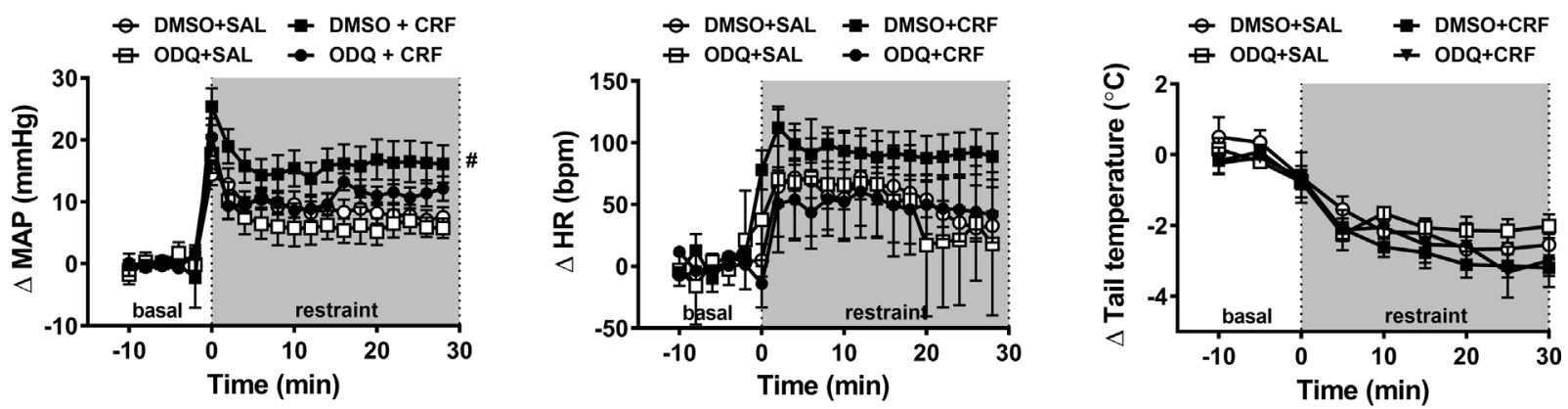

IA $8.74 \mathrm{~mm}$

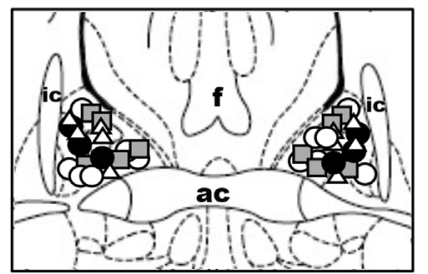

$\mathrm{Veh}+\mathrm{Veh}$

- ODQ + Veh

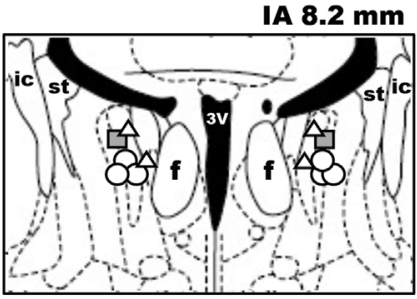

$\square \mathrm{Veh}+\mathrm{CRF}$

$\triangle O D Q+C R F$

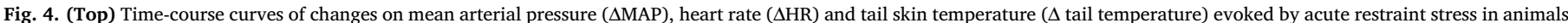

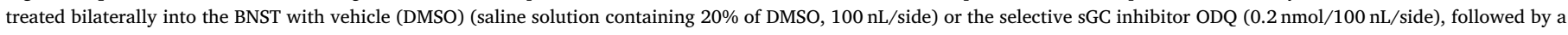

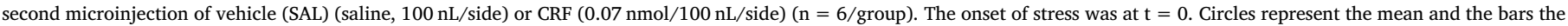

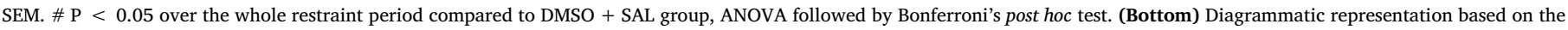

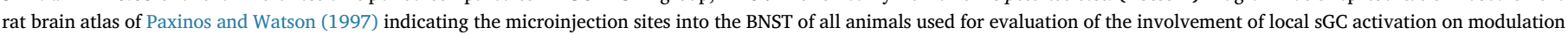

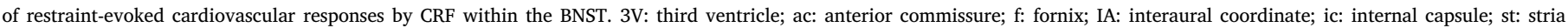
terminalis.

CRF (Bale and Vale, 2004; Hauger et al., 2003). The peptides of CRF system differently bind to $\mathrm{CRF}_{1}$ and $\mathrm{CRF}_{2}$ receptors. For instance, $\mathrm{CRF}$ selectively binds to the $\mathrm{CRF}_{1}$ receptor, Ucn1 has similar affinity to both receptors, whereas Ucn2 and Ucn3 are selective ligands of the $\mathrm{CRF}_{2}$ receptor (Hauger et al., 2003).

The BNST anterior division is proposed as the critical region involved in control of autonomic activity and cardiovascular function (Crestani et al., 2013; Dong et al., 2001). This idea is supported by neuroanatomical results demonstrating that the anterior division is the preferential region of the BNST connected with hypothalamic and lower brainstem regions involved in control of autonomic activity (Dong et al., 2001; Dong and Swanson, 2004), as well as by functional studies
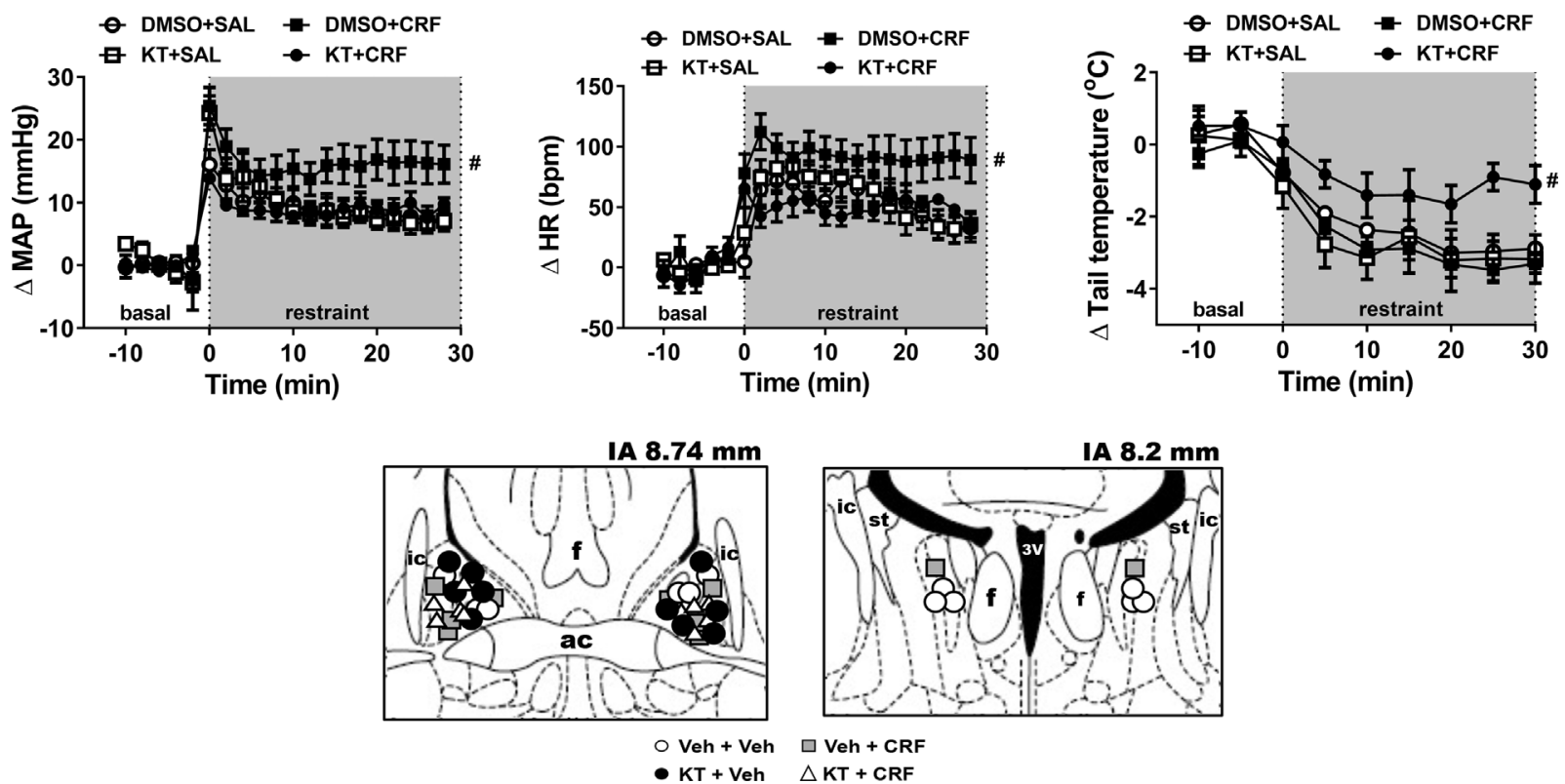

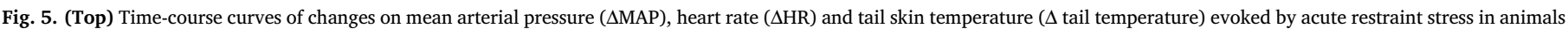

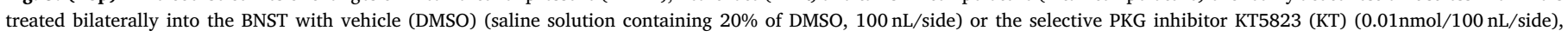

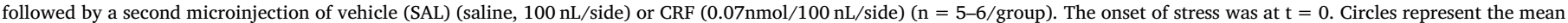

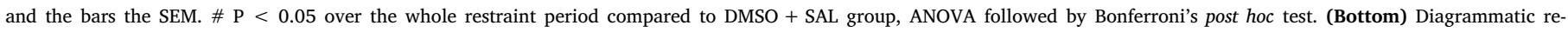

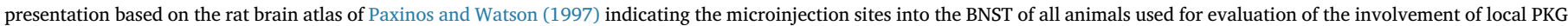

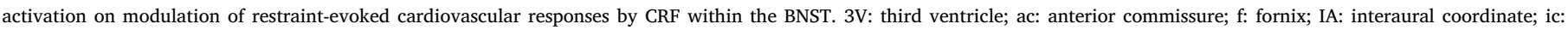
internal capsule; st: stria terminalis. 
reporting that largest cardiovascular responses are elicited more often when this region of the BNST is stimulated (Ciriello and Janssen, 1993; Zhang et al., 2009). Accordingly, most of the microinjection sites in the present study reached regions of the BNST anterior division. Indeed, both $\mathrm{CRF}_{1}$ and $\mathrm{CRF}_{2}$ receptors were reported to be expressed in nuclei of the BNST anterior division (Dabrowska et al., 2011; Van Pett et al., 2000). Besides, terminals immunoreactive for CRF and Ucn1- and Ucn3immunoreactive fibers were found within rostral regions of the BNST (Bittencourt et al., 1999; Li et al., 2002). Local neurons immunoreactive for CRF and Ucn3 were also identified within the BNST anterior division (Li et al., 2002; Phelix and Paull, 1990; Swanson et al., 1983). Altogether, these pieces of evidence support present findings indicating a modulation of restraint-evoked cardiovascular responses by CRF microinjection into rostral regions of the BNST.

Previous studies from our group revealed a role of CRF neurotransmission present within the regions of the BNST anterior division in control of cardiovascular responses to restraint stress. For instance, we reported that microinjection of a selective $\mathrm{CRF}_{1}$ receptor antagonist into rostral regions of the BNST dose-dependently decreased the increase on arterial pressure and HR evoked by acute restraint stress, whereas a selective $\mathrm{CRF}_{2}$ receptor antagonist decreased the pressor response and the sympathetically-mediated cutaneous vasoconstriction during restraint stress (Oliveira et al., 2015). Conversely, BNST treatment with either the selective $\mathrm{CRF}_{1}$ receptor agonist CRF or the selective $\mathrm{CRF}_{2}$ receptor agonist Ucn3 enhanced the restraint-evoked cardiovascular changes (Oliveira et al., 2015). Therefore, enhances of arterial pressure and HR evoked by CRF microinjection into the BNST reported in the present study are in line with results previously reported.

Results obtained using electrophysiological techniques indicated that CRF acts presynaptically via $\mathrm{CRF}_{1}$ receptor to increase glutamatergic neurotransmission within the BNST anterior division (Silberman and Winder, 2013). It was evidenced by demonstration that CRF application onto BNST in vitro increased frequency, but not amplitude, of SEPSC; and this effect was inhibited by pretreatment with a selective $\mathrm{CRF}_{1}$ receptor antagonist (Kash et al., 2008; Silberman et al., 2013). This CRF-mediated facilitation of glutamatergic neurotransmission within the BNST has been implicated in drug addiction, as evidenced by demonstration that this neurochemical mechanism is recruited following chronic exposure to alcohol and cocaine (Kash et al., 2008; Nobis et al., 2011; Silberman et al., 2013). However, present findings provide the first evidence that CRF-glutamate interaction within the BNST in involved in control of physiological responses during aversive threats. Furthermore, results reported in the present study indicate a novel interaction between CRF and nitrergic signaling within rostral regions of the BNST, which plays a role in the control of stress-evoked cardiovascular responses.

An additional component of BNST CRF neurocircuitry is a noradrenaline-CRF interaction (Silberman and Winder, 2013). In this sense, data from electrophysiological studies indicated that noradrenaline released within the BNST anterior division activates local neurons synthetizing CRF (Silberman et al., 2013), which likely increase local CRF levels (Silberman and Winder, 2013). In turn, the enhanced CRF levels increase BNST glutamatergic activity, thus increasing local excitation (Nobis et al., 2011; Silberman et al., 2013). A role of noradrenergic neurotransmission present in the BNST anterior division in control of restraint-evoked cardiovascular changes was previously reported (Crestani et al., 2013). Indeed, BNST treatment with a selective $\alpha_{1}$-adrenoceptor antagonist, but not with selective $\alpha_{2}$-adrenoceptor or $\beta$-adrenoceptor antagonists, enhanced the tachycardia evoked by restraint stress without affecting the pressor response (Crestani et al., 2009). Despite these pieces of evidence, the report of an inhibitory role of BNST noradrenergic neurotransmission in restraint-evoked cardiovascular changes (Crestani et al., 2013; Crestani et al., 2009) precludes the idea that the facilitatory influence of local CRF neurotransmission in control of cardiovascular responses to stress is related to local noradrenaline release. Therefore, release of CRF and the related peptides within the BNST during restraint stress seems to be mediated by independent mechanisms of local noradrenergic neurotransmission. In this regard, in addition to intrinsic sources (i.e., from local BNST CRFsynthesizing neurons), CRF and the related peptides may also be released from extrinsic source, such as terminals arising from the central nucleus of the amygdala (CeA) and paraventricular nucleus of the hypothalamus (PVN) (Vranjkovic et al., 2017). In this sense, similar to BNST CRF neurotransmission, a facilitatory role of both CeA and PVN in modulation of cardiovascular responses to stress was previously reported (Busnardo et al., 2013; Busnardo et al., 2010b; Sanders et al., 1994), thus supporting the idea that CRF and the related peptides can be released into the BNST from terminals coming from other limbic structures.

Cardiovascular responses during aversive threats are mediated by changes on activity of both sympathetic and parasympathetic nervous system (Crestani, 2016). For instance, increase on HR during aversive threats is abolished following inhibition of cardiac sympathetic activity, while blockade of parasympathetic tone to the heart increases this response (Carrive, 2006; Dos Reis et al., 2014), thus suggesting a coativation of cardiac sympathetic and parasympathetic activity during stress. The pressor response during stress is inhibited following treatment with $\alpha_{1}$-adrenoceptor antagonists (Crestani, 2016; Dos Reis et al., 2014), thus indicating that vasoconstriction in splanchnic, renal and cutaneous beds (Blessing, 2003; Schadt and Hasser, 1998; Zhang et al., 1996) contribute to pressor response. Neurons in the anterior division of the BNST project to medullary structures controlling autonomic activity, such as the nucleus of the solitary tract, nucleus ambiguus, and ventrolateral regions (Dong and Swanson, 2004; Gray and Magnuson, 1987). Therefore, the facilitatory role of CRF in the BNST on restraintevoked tachycardia may be mediated by stimulation of either facilitatory drive to sympathetic premotor neurons or inhibitory pathways to parasympathetic neurons in the medulla, whereas facilitation of pressor response is mediated by a sympathetic facilitation.

A surprising finding was the decreased drop in tail skin temperature response identified in animals subjected to combined treatment with KT5823 plus CRF into the BNST (i.e., KT + CRF group). The mechanism related to this effect is unclear. However, the blockade of the PKG unmasked an effect of CRF decreasing the restraint-evoked cutaneous vasoconstriction. In this sense, although the present findings indicate that CRF control of cardiovascular responses to stress within the BNST is mediated by facilitation of local glutamatergic neurotransmission and activation of nitric oxide signaling, the decreased tail skin temperature response found in $\mathrm{KT}+\mathrm{CRF}$ group provides evidence that CRF can also interacts with other local neurochemical mechanisms controlling the sympathetically-mediated cutaneous vasoconstriction, which seem to counteract the effect mediated by PKG activation. As stated above, previous studies reported an interaction of CRF neurotransmission with local noradrenergic neurotransmission within the BNST (Silberman and Winder, 2013). However, a role of BNST noradrenergic neurotransmission in control of cutaneous vasoconstriction response to restraint stress has never been evaluated. Besides, we cannot exclude the possibility that this effect is independent of interaction with other neurotransmitters, being able to be mediated by a direct action of CRF in central pathways controlling the sympathetic activity. Anyway, further studies are necessary to clarify the mechanisms involved in this effect.

In summary, results of the present study provide evidence that CRF activates local NMDA-mediated excitation and nitrergic signaling within the BSNT. Furthermore, our data suggest that facilitatory influence of BNST CRF neurotransmission on cardiovascular responses evoked by aversive stimuli are mediated by activation of local NMDA glutamate receptor, nNOS, sGC and PKG. 


\section{Role of funding source}

Funding for this study was provided by FAPESP (grants \# 2015/ 05922-9) and CNPq (grant \# 456405/2014-3). The FAPESP and CNPq had no further role in study design; in the collection, analysis and interpretation of data; in the writing of the report; and in the decision to submit the paper for publication.

\section{Contributors}

L.A.O. and C.C.C. conceived and designed this research; L.A.O., L.G.S. and R.B. performed the experiments and analyzed the data; L.A.O., L.G.S. and R.B. and C.C.C. interpreted the results of experiments; L.A.O. prepared the figures and drafted the manuscript; L.A.O. and C.C.C. edited and revised the manuscript; C.C.C. approved the final version of the manuscript.

\section{Conflicts of interest}

None.

\section{Acknowledgements}

The authors wish to acknowledge Rosana Silva and Elisabete Lepera for technical assistance. The present research was supported by grants from FAPESP (grants \# 2015/05922-9), CNPq (grant \# 456405/20143 ), and Scientific Support and Development Program of School of Pharmaceutical Sciences (UNESP). CCC is a CNPq research fellow (process \# 305583/2015-8).

\section{Appendix A. Supplementary data}

Supplementary data associated with this article can be found, in the online version, at https://doi.org/10.1016/j.psyneuen.2018.01.010.

\section{References}

Adami, M.B., Barretto-de-Souza, L., Duarte, J.O., Almeida, J., Crestani, C.C., 2017. Both $N$-methyl-D-aspartate and non- $N$-methyl-D-aspartate glutamate receptors in the bed nucleus of the stria terminalis modulate the cardiovascular responses to acute restraint stress in rats. J. Psychopharmacol. 31, 674-681.

Alves, F.H., Crestani, C.C., Resstel, L.B., Correa, F.M., 2009. Bed nucleus of the stria terminalis $N$-methyl-D-aspartate receptors and nitric oxide modulate the baroreflex cardiac component in unanesthetized rats. J. Neurosci. Res. 87, 1703-1711.

Bale, T.L., Vale, W.W., 2004. CRF and CRF receptors: role in stress responsivity and other behaviors. Annu. Rev. Pharmacol. Toxicol. 44, 525-557.

Bittencourt, J.C., Vaughan, J., Arias, C., Rissman, R.A., Vale, W.W., Sawchenko, P.E. 1999. Urocortin expression in rat brain: evidence against a pervasive relationship of urocortin-containing projections with targets bearing type 2 CRF receptors. J. Comp. Neurol. 415, 285-312.

Blessing, W.W., 2003. Lower brainstem pathways regulating sympathetically mediated changes in cutaneous blood flow. Cell. Mol. Neurobiol. 23, 527-538.

Busnardo, C., Crestani, C.C., Tavares, R.F., Resstel, L.B., Correa, F.M., 2010a. Cardiovascular responses to L-glutamate microinjection into the hypothalamic paraventricular nucleus are mediated by a local nitric oxide-guanylate cyclase mechanism. Brain Res. 1344, 87-95.

Busnardo, C., Tavares, R.F., Resstel, L.B., Elias, L.L., Correa, F.M., 2010b. Paraventricular nucleus modulates autonomic and neuroendocrine responses to acute restraint stress in rats. Auton. Neurosci. 158, 51-57.

Busnardo, C., Alves, F.H., Crestani, C.C., Scopinho, A.A., Resstel, L.B., Correa, F.M., 2013. Paraventricular nucleus of the hypothalamus glutamate neurotransmission modulates autonomic, neuroendocrine and behavioral responses to acute restraint stress in rats. Eur. Neuropsychopharmacol. 23, 1611-1622.

Camargo, L.H., Alves, F.H., Biojone, C., Correa, F.M., Resstel, L.B., Crestani, C.C., 2013. Involvement of $N$-methyl-D-aspartate glutamate receptor and nitric oxide in cardiovascular responses to dynamic exercise in rats. Eur. J. Pharmacol. 713, 16-24.

Carrive, P., 2006. Dual activation of cardiac sympathetic and parasympathetic components during conditioned fear to context in the rat. Clin. Exp. Pharmacol. Physiol. 33, $1251-1254$.

Ciriello, J., Janssen, S.A., 1993. Effect of glutamate stimulation of bed nucleus of the stria terminalis on arterial pressure and heart rate. Am. J. Physiol. 265, H1516-1522.

Crestani, C.C., Alves, F.H., Tavares, R.F., Correa, F.M., 2009. Role of the bed nucleus of the stria terminalis in the cardiovascular responses to acute restraint stress in rats. Stress $12,268-278$.
Crestani, C.C., Tavares, R.F., Alves, F.H., Resstel, L.B., Correa, F.M., 2010. Effect of acute restraint stress on the tachycardiac and bradycardiac responses of the baroreflex in rats. Stress 13, 61-72.

Crestani, C.C., Alves, F.H., Gomes, F.V., Resstel, L.B., Correa, F.M., Herman, J.P., 2013. Mechanisms in the bed nucleus of the stria terminalis involved in control of autonomic and neuroendocrine functions: a review. Curr. Neuropharmacol. 11, 141-159.

Crestani, C.C., 2016. Emotional stress and cardiovascular complications in animal models: a review of the influence of stress type. Front. Physiol. 7, 251.

Dabrowska, J., Hazra, R., Ahern, T.H., Guo, J.D., McDonald, A.J., Mascagni, F., Muller, J.F., Young, L.J., Rainnie, D.G., 2011. Neuroanatomical evidence for reciprocal regulation of the corticotrophin-releasing factor and oxytocin systems in the hypothalamus and the bed nucleus of the stria terminalis of the rat: implications for balancing stress and affect. Psychoneuroendocrinology 36, 1312-1326.

Dampney, R.A., 2015. Central mechanisms regulating coordinated cardiovascular and respiratory function during stress and arousal. Am. J. Physiol. Regul. Integr. Comp. Physiol. 309, R429-443.

Daniel, S.E., Rainnie, D.G., 2016. Stress modulation of opposing circuits in the bed nucleus of the stria terminalis. Neuropsychopharmacology 41, 103-125.

Davis, M., Walker, D.L., Miles, L., Grillon, C., 2010. Phasic vs sustained fear in rats and humans: role of the extended amygdala in fear vs anxiety. Neuropsychopharmacology 35, 105-135.

Dong, H.W., Swanson, L.W., 2004. Organization of axonal projections from the anterolateral area of the bed nuclei of the stria terminalis. J. Comp. Neurol. 468, 277-298.

Dong, H.W., Petrovich, G.D., Swanson, L.W., 2001. Topography of projections from amygdala to bed nuclei of the stria terminalis. Brain Res. Brain Res. Rev. 38, 192-246.

Dos Reis, D.G., Fortaleza, E.A., Tavares, R.F., Correa, F.M., 2014. Role of the autonomic nervous system and baroreflex in stress-evoked cardiovascular responses in rats. Stress $17,362-372$.

Garthwaite, J., 2008. Concepts of neural nitric oxide-mediated transmission. Eur. J. Neurosci. 27, 2783-2802.

Gray, T.S., Magnuson, D.J., 1987. Neuropeptide neuronal efferents from the bed nucleus of the stria terminalis and central amygdaloid nucleus to the dorsal vagal complex in the rat. J. Comp. Neurol. 262, 365-374.

Guimaraes, F.S., Beijamini, V., Moreira, F.A., Aguiar, D.C., de Lucca, A.C., 2005. Role of nitric oxide in brain regions related to defensive reactions. Neurosci. Biobehav. Rev. 29, 1313-1322.

Hauger, R.L., Grigoriadis, D.E., Dallman, M.F., Plotsky, P.M., Vale, W.W., Dautzenberg, F.M., 2003. International Union of Pharmacology: XXXVI. Current status of the nomenclature for receptors for corticotropin-releasing factor and their ligands. Pharmacol. Rev. 55, 21-26.

Hofmann, F., Feil, R., Kleppisch, T., Schlossmann, J., 2006. Function of cGMP-dependent protein kinases as revealed by gene deletion. Physiol. Rev. 86, 1-23.

Hott, S.C., Gomes, F.V., Uliana, D.L., Vale, G.T., Tirapelli, C.R., Resstel, L.B., 2017. Bed nucleus of the stria terminalis NMDA receptors and nitric oxide modulate contextual fear conditioning in rats. Neuropharmacology 112, 135-143.

Kash, T.L., Nobis, W.P., Matthews, R.T., Winder, D.G., 2008. Dopamine enhances fast excitatory synaptic transmission in the extended amygdala by a CRF-R1-dependent process. J. Neurosci. 28, 13856-13865.

Li, C., Vaughan, J., Sawchenko, P.E., Vale, W.W., 2002. Urocortin III-immunoreactive projections in rat brain: partial overlap with sites of type 2 corticotrophin-releasing factor receptor expression. J. Neurosci. 22, 991-1001.

Myers, B., 2017. Corticolimbic regulation of cardiovascular responses to stress. Physiol. Behav. 172, 49-59.

Nijsen, M.J., Croiset, G., Diamant, M., De Wied, D., Wiegant, V.M., 2001. CRH signalling in the bed nucleus of the stria terminalis is involved in stress-induced cardiac vagal activation in conscious rats. Neuropsychopharmacology 24, 1-10.

Nobis, W.P., Kash, T.L., Silberman, Y., Winder, D.G., 2011. Beta-adrenergic receptors enhance excitatory transmission in the bed nucleus of the stria terminalis through a corticotrophin-releasing factor receptor-dependent and cocaine-regulated mechanism. Biol. Psychiatry 69, 1083-1090.

Oliveira, L.A., Almeida, J., Benini, R., Crestani, C.C., 2015. CRF1 and CRF2 receptors in the bed nucleus of the stria terminalis modulate the cardiovascular responses to acute restraint stress in rats. Pharmacol. Res. 95-96, 53-62.

Paxinos, G., Watson, C., 1997. The Rat Brain in Stereotaxic Coordinates, 3 ed. Academic Press Sidney, Australia.

Phelix, C.F., Paull, W.K., 1990. Demonstration of distinct corticotropin releasing factor-containing neuron populations in the bed nucleus of the stria terminalis. A light and electron microscopic immunocytochemical study in the rat. Histochemistry 94, 345-364.

Prast, H., Philippu, A., 2001. Nitric oxide as modulator of neuronal function. Prog. Neurobiol. 64, 51-68.

Sanders, B.J., Wirtz-Nole, C., DeFord, S.M., Erling, B.F., 1994. Central amygdaloid lesions attenuate cardiovascular responses to acute stress in rats with borderline hypertension. Physiol. Behav. 56, 709-713.

Schadt, J.C., Hasser, E.M., 1998. Hemodynamic effects of acute stressors in the conscious rabbit. Am. J. Physiol. 274, R814-821.

Silberman, Y., Winder, D.G., 2013. Emerging role for corticotropin releasing factor signaling in the bed nucleus of the stria terminalis at the intersection of stress and reward. Front. Psychiatry 4, 42

Silberman, Y., Matthews, R.T., Winder, D.G., 2013. A corticotropin releasing factor pathway for ethanol regulation of the ventral tegmental area in the bed nucleus of the stria terminalis. J. Neurosci. 33, 950-960.

Silva, M., Aguiar, D.C., Diniz, C.R., Guimaraes, F.S., Joca, S.R., 2012. Neuronal NOS inhibitor and conventional antidepressant drugs attenuate stress-induced fos expression in overlapping brain regions. Cell. Mol. Neurobiol. 32, 443-453. 
Sterling, P., 2012. Allostasis: a model of predictive regulation. Physiol. Behav. 106, 5-15. Swanson, L.W., Sawchenko, P.E., Rivier, J., Vale, W.W., 1983. Organization of ovine corticotropin-releasing factor immunoreactive cells and fibers in the rat brain: an immunohistochemical study. Neuroendocrinology 36, 165-186.

Ulrich-Lai, Y.M., Herman, J.P., 2009. Neural regulation of endocrine and autonomic stress responses. Nat. Rev. Neurosci. 10, 397-409.

Van Pett, K., Viau, V., Bittencourt, J.C., Chan, R.K., Li, H.Y., Arias, C., Prins, G.S., Perrin, M., Vale, W., Sawchenko, P.E., 2000. Distribution of mRNAs encoding CRF receptors in brain and pituitary of rat and mouse. J. Comp. Neurol. 428, 191-212.

Vianna, D.M., Carrive, P., 2005. Changes in cutaneous and body temperature during and after conditioned fear to context in the rat. Eur. J. Neurosci. 21, 2505-2512.
Vincent, S.R., Kimura, H., 1992. Histochemical mapping of nitric oxide synthase in the rat brain. Neuroscience 46, 755-784.

Vranjkovic, O., Pina, M., Kash, T.L., Winder, D.G., 2017. The bed nucleus of the stria terminalis in drug-associated behavior and affect: a circuit-based perspective. Neuropharmacology 122, 100-106.

Zhang, Z.Q., Julien, C., Barres, C., 1996. Baroreceptor modulation of regional haemodynamic responses to acute stress in rat. J. Auton. Nerv. Syst. 60, 23-30.

Zhang, W., Zhang, N., Sakurai, T., Kuwaki, T., 2009. Orexin neurons in the hypothalamus mediate cardiorespiratory responses induced by disinhibition of the amygdala and bed nucleus of the stria terminalis. Brain Res. 1262, 25-37. 